\title{
The Role and Impact of Social Media in Cardio-oncology During the COVID-19 Pandemic
}

\author{
Jennifer M. Kwan ${ }^{1} \cdot$ Mariana L. Henry ${ }^{2} \cdot$ Briana Christophers $^{3} \cdot$ Kamala Tamirisa $^{4} \cdot$ Ritu Thamman $^{5} \cdot$ Diego Sadler $^{6}$. \\ Niti R. Aggarwal ${ }^{7} \cdot$ Richard Cheng $^{8} \cdot$ Purvi Parwani $^{9} \cdot$ Susan Dent $^{10} \cdot$ Roohi Ismail-Khan ${ }^{11} \cdot$ Michael G. Fradley $^{12} \cdot$ \\ Sherry-Ann Brown ${ }^{13}$
}

Accepted: 30 April 2021 / Published online: 14 July 2021

(C) The Author(s), under exclusive licence to Springer Science+Business Media, LLC, part of Springer Nature 2021

\begin{abstract}
Purpose of Review To give an overview of the role of social media (SoMe) in cardio-oncology during the COVID-19 pandemic. Recent Findings SoMe has been critical in fostering education, outreach, awareness, collaboration, dissemination of information, and advocacy in cardio-oncology. This has become increasingly evident during the COVID-19 pandemic, during which SoMe has helped share best practices, community, and research focused on the impact of COVID-19 in cardiology and hematology/ oncology, with cardio-oncology at the interface of these two subspecialty fields.

Summary A strength of SoMe is the ability to amplify a message in real-time, globally, with minimal investment of resources. This has been particularly beneficial for the emerging field of cardio-hematology/cardio-oncology, a field focused on the interplay of cancer and cardiovascular disease. SoMe field especially during the COVID-19 pandemic. We illustrate how social media has supported innovation (including telemedicine), amplification of healthcare workers' voice, and illumination of pre-existing and continued health disparities within the field of cardio-oncology during the pandemic.
\end{abstract}

Keywords Social media $\cdot$ Cardio-oncology $\cdot$ COVID-19 $\cdot$ Health disparities $\cdot$ Pandemic $\cdot$ Advocacy

\section{Introduction}

Cardiovascular disease is the second leading cause of death in cancer survivors, following recurrence of the primary cancer or diagnosis with a secondary malignancy [1]. In 2019, there were 17 million cancer survivors in the USA, and it is

This article is part of the Topical Collection on Cardio-oncology

Sherry-Ann Brown

shbrown@mcw.edu

1 Section of Cardiovascular Medicine, Yale School of Medicine, New Haven, CT, USA

2 Dartmouth School of Medicine, Lebanon, NH, USA

3 Weill Cornell/Rockefeller/Sloan Kettering Tri-Institutional MD-PhD program, New York, NY, USA

4 Texas Cardiac Arrhythmia Institute, Austin, TX, USA

5 University of Pittsburg, Pittsburg, PA, USA

6 Cleveland Clinic, Weston, FL, USA

7 Department of Cardiovascular Diseases, Mayo Clinic, Rochester, MN, USA estimated that there will be 22 million by 2030 [2]. Cardiooncology is an emerging discipline that addresses this unique population and is centered on preventing, monitoring, and treating cardiovascular toxicity from pharmacologic and radiation cancer therapies. Cardio-oncology is a relatively young field, and a wealth of information is rapidly being produced,

8 Division of Cardiology, University of Washington, Seattle, WA, USA

9 Loma Linda University Health, Loma Linda, CA, USA

10 Division of Medical Oncology, Duke Cancer Institute, Duke University, Durham, NC, USA

11 Cardio-Oncology Program, H. Lee Moffitt Cancer Center, University of South Florida, Tampa, FL, USA

12 Cardio-Oncology Center of Excellence, Division of Cardiology, Department of Medicine, Perelman School of Medicine at the University of Pennsylvania, Philadelphia, PA, USA

13 Cardio-Oncology Program, Division of Cardiovascular Medicine, Medical College of Wisconsin, 8701 Watertown Plank Road, Milwaukee, WI 53226, USA 
due to the increasing recognition of cancer therapy-related cardiovascular toxicity, the growing number of cancer survivors, and research in this interdisciplinary field [2]. However, there is still limited knowledge of this field among most healthcare professionals and patients. Thus, efforts are needed to increase awareness.

The development of cardio-oncology has occurred in parallel with the increasing presence of social media in medicine. SoMe platforms such as Twitter, Facebook, Instagram, and LinkedIn have been critical in spreading awareness of cardiooncology, enabling advocacy for clinicians and patients, and providing online resources. Given that this field is in its early stages, social media has been important in helping clinicians and researchers navigate in real-time novel research findings, as well as providing the opportunity to connect, share discoveries, and discuss cardio-oncologic care [3-12]. Aligning with the rapid progress and novel therapies in cancer treatment, knowledge of the cardiovascular impact of these cancer therapies continues to grow at an exponential pace and is well suited for the real-time environment of SoMe. Furthermore, as a foundation for networking and collaboration, SoMe has been essential in bridging the fields of cardiology and hematology/ oncology [2]. Additionally, the use of mobile health platforms has been promoted and highlighted on SoMe to enable earlier detection and better management of disease states in cardiooncology, such as arrhythmias and heart failure. Using artificial intelligence to distinguish signatures of disease versus health states in continuous biosensor data, and perhaps using artificial intelligence to analyze the social media posts themselves to detect relevant trends in dissemination of information, may help enable the optimization of innovation for patients and healthcare workers in cardio-oncology [13-15].

In this review, we present examples of these roles of SoMe, highlighting studies leveraging SoMe during the initial shut down due to the peak of the pandemic, and its interplay in cardio-oncology. This study highlights quantitative and qualitative data supporting the efficacy of using Twitter for educational and advocacy campaigns in cardio-oncology, as well as the ability to rapidly disseminate medical information to a large, widespread audience [16, 17].

\section{The Rise of \#COVID-19}

On March 11, 2020, the World Health Organization declared the novel coronavirus disease of 2019 (COVID-19) a pandemic. As of March 2021, COVID-19 had infected 122 million individuals, killing more than 2.6 million around the world and more than 539,000 in the USA [18]. COVID-19 has demonstrated wideranging effects on all organ systems, resulting in respiratory failure, heart failure, myocarditis, strokes, chronic neurologic symptoms, kidney failure, and gastroenteritis, among other manifestations of organ toxicity [19]. Early data have demonstrated that individuals with underlying heart disease or cancer experience worse clinical outcomes [19-25]. Furthermore, cancer patients are at increased risk of cardiovascular disease/myocardial infarction due to shared risk factors, cancer itself and its [26] and various antineoplastic therapies, including increased risk of atherosclerosis or myocardial infarction with agents such as checkpoint inhibitors or $5 \mathrm{FU}[27,28]$. Many of these high-risk, immunocompromised patients also experience decreased access to cardiovascular care during the pandemic, due to nonessential tests being postponed to help preserve personal protective equipment and reduce unnecessary exposure [29]. Voluntary avoidance of the healthcare system by these patients led to many not seeking care even after developing cardiac symptoms [30]. Added stressors from the pandemic are likely to worsen the situation on top of the added stress of a cancer diagnosis, trying to navigate therapy, follow-up, and particularly for those whose cardiovascular health has been affected by their cancer therapy.

COVID-19 has also had a devastating impact worldwide, leading to large-scale forced isolation, death, and economic instability [31]. Healthcare workers, in particular, have been at increased risk of psychological distress due to the pandemic, leading to reflections of appreciation of healthcare and frontline workers on SoMe. As interactions have moved to online platforms, SoMe has been a platform to boost camaraderie and community, including among health professionals in cardio-oncology $[2,13,16,32]$.

SoMe platforms such as Twitter (www.twitter.com), Instagram (www.instagram.com), Facebook (www. facebook.com), and YouTube (www.youtube.com) have been critical in helping healthcare workers and the general public keep pace with the exponential increase in updates and information on COVID-19 (Table 1). They can also serve several purposes. In brief, Twitter allows for users to share "Tweets" or short statements and phrases that can serve to update, educate, or promote advocacy to the user's followers. Instagram allows for sharing of photos and short videos which can serve to update, entertain, advertise or promote advocacy to the user's followers. YouTube allows users to share videos which can serve as a platform for entertainment, advocacy, and education. Facebook gives users the power to share all of these forms of media, enabling users to keep up to date with other users such as friends, family, and colleagues whom they add as "friends." Hashtags are common to all of these platforms. A hashtag is a metadata tag that is prefaced by the hash symbol (\#) and is user-generated that enables crossreferencing of content sharing of a subject or theme.

A recent study found that among 453 healthcare workers, $61 \%$ of participants used SoMe to obtain information on COVID-19 [33]. SoMe has been used to spread awareness about COVID-19 and counter the spread of misinformation $[34,35]$. Moreover, as the suggested treatments and care for patients with COVID-19 and cancer or cardiovascular disease have been quickly transformed, SoMe has been critical for helping health professionals and researchers navigate these 
Table 1 Use of social media to educate and disseminate information on Cardio-oncology research and care during the pandemic

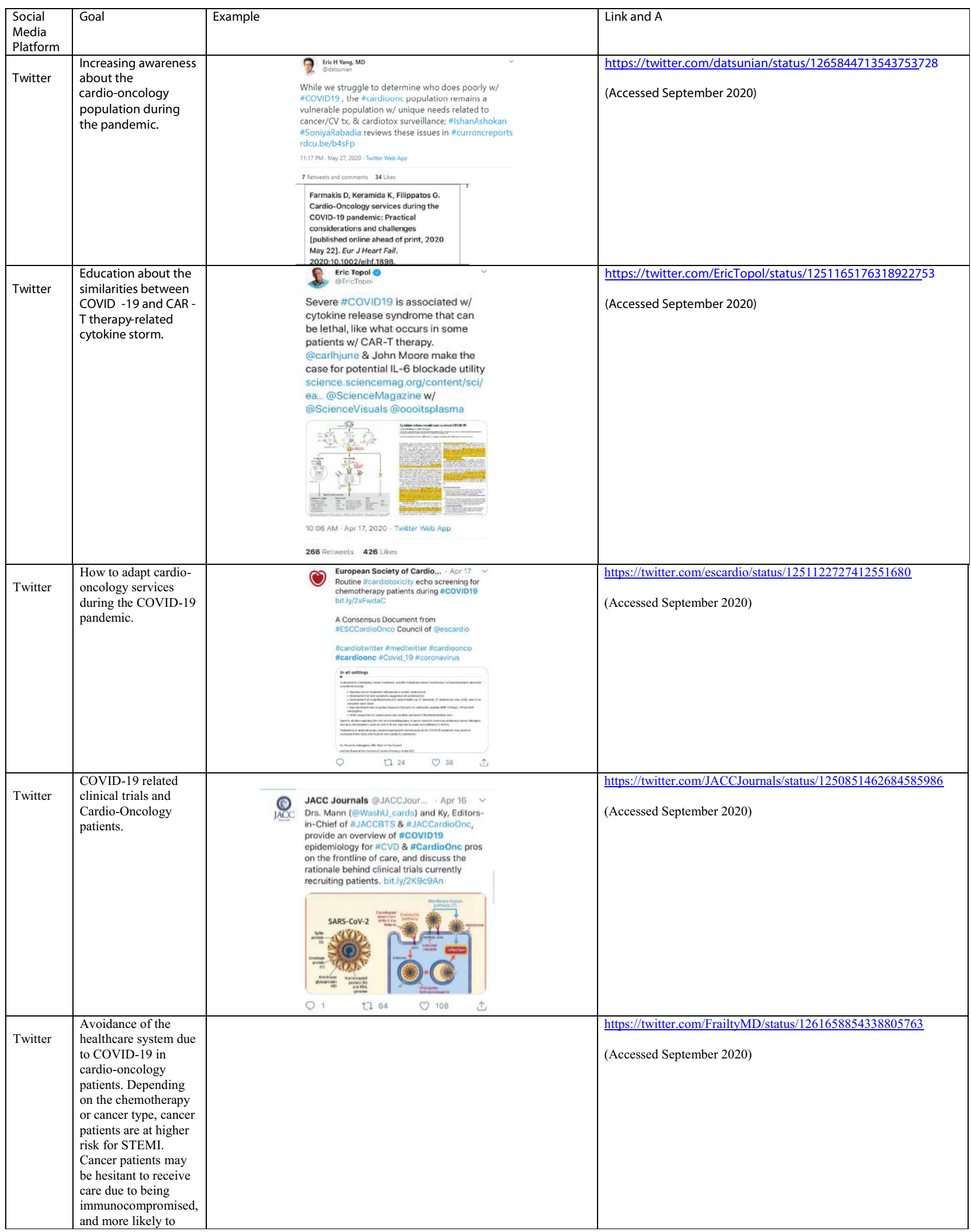

See online collage: \#COVID-19 \#Cardiooncology SoMe Collection capturing the pulse of the COVID-19 pandemic (http://cardiooncology.s3-websiteus-west-2.amazonaws.com/ 
Table 1 (continued)

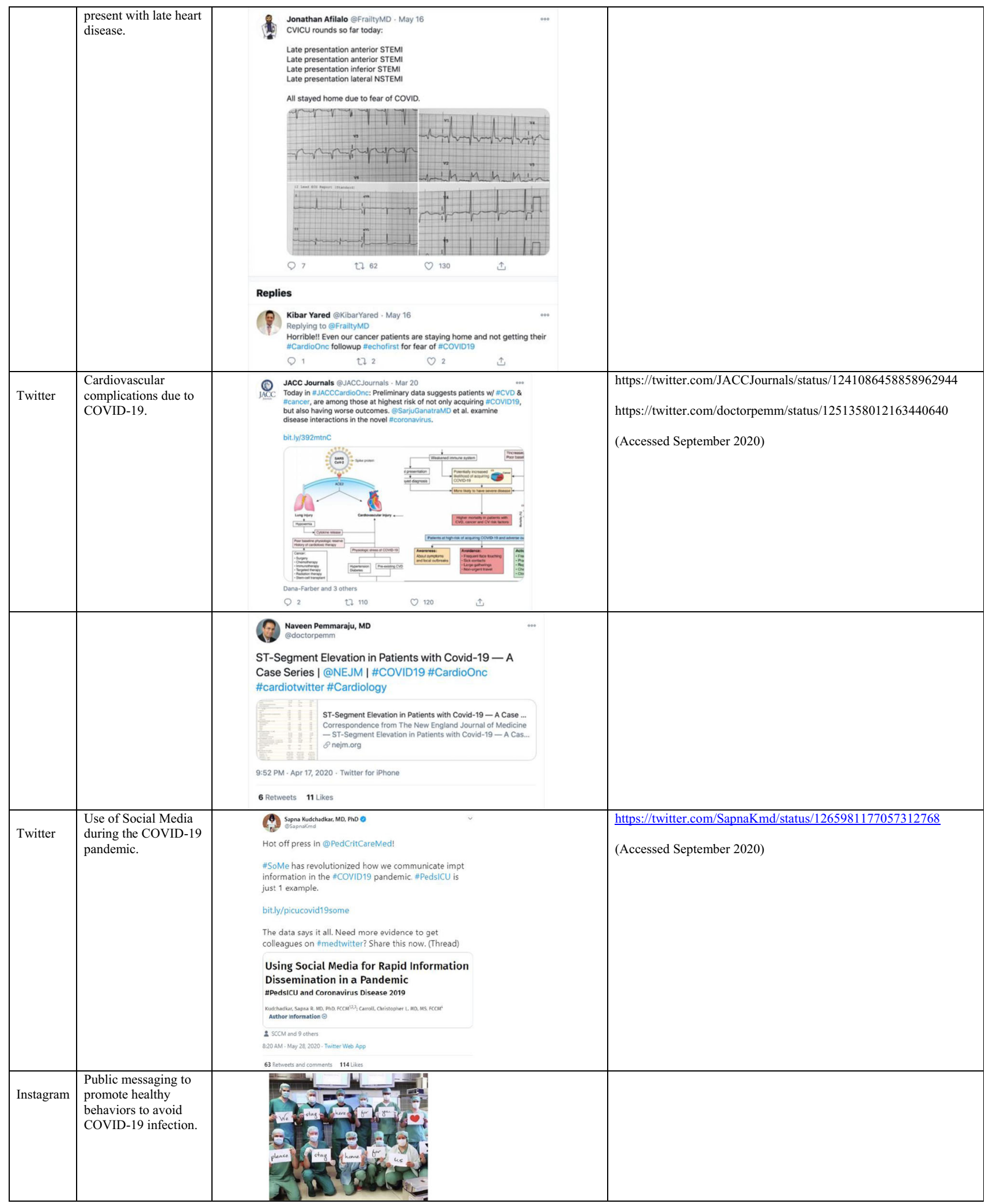


Table 1 (continued)

\begin{tabular}{|c|c|c|c|}
\hline Twitter & $\begin{array}{l}\text { SoMe as an aid to } \\
\text { help the public } \\
\text { determine whether to } \\
\text { do cancer screenings. }\end{array}$ & 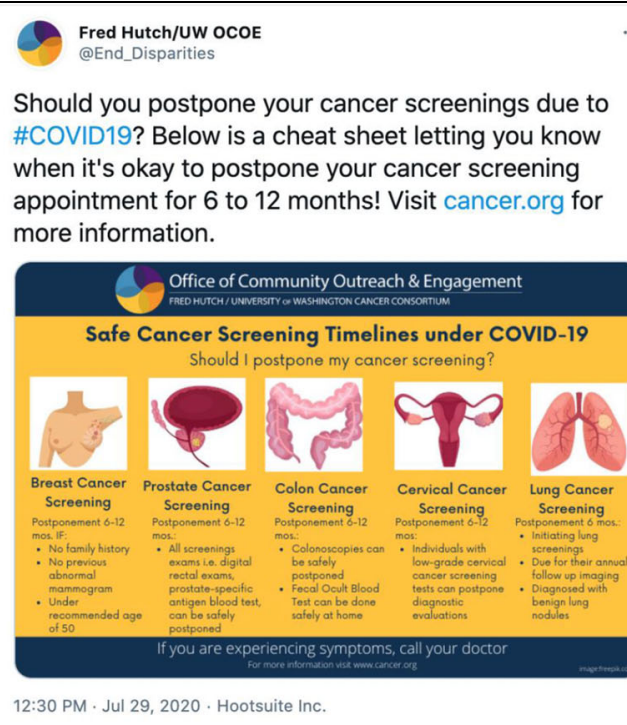 & $\begin{array}{l}\text { https://twitter.com/End_Disparities/status/1288512271300415489 } \\
\text { (Accessed February 2021) }\end{array}$ \\
\hline Twitter & $\begin{array}{l}\text { Messaging to promote } \\
\text { prioritization of } \\
\text { vaccination for } \\
\text { oncology patients. }\end{array}$ & 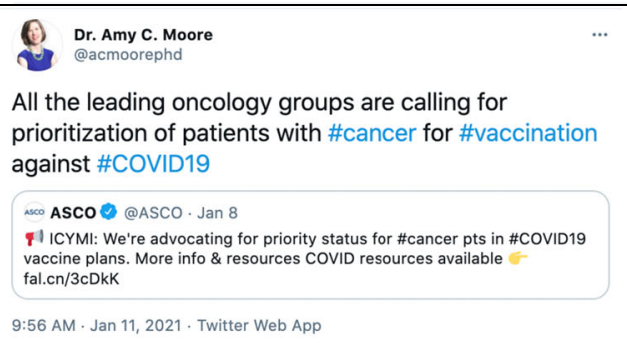 & $\begin{array}{l}\text { https://twitter.com/acmoorephd/status/1348645027006664705 } \\
\text { (Accessed February 2021) }\end{array}$ \\
\hline Twitter & $\begin{array}{l}\text { COVID-19 delaying } \\
\text { cancer care and } \\
\text { screening, and } \\
\text { increasing the risk of } \\
\text { cancer death }\end{array}$ & 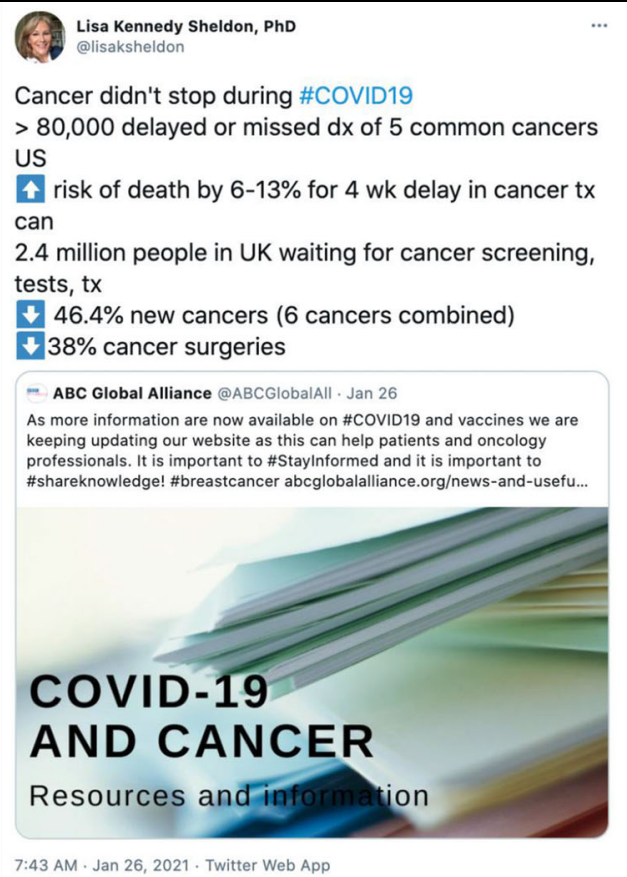 & $\begin{array}{l}\text { https://twitter.com/lisaksheldon/status/1354047207515836417 } \\
\text { (Accessed February 2021) }\end{array}$ \\
\hline
\end{tabular}

changes in care, as well as disperse new research and findings. Such platforms have also served educational purposes that can lead to systemic change. SoMe has been used to highlight and amplify health, social, and racial disparities in the USA. African Americans and Hispanics are more likely to be infected and die from the virus or its associated complications [36]. 
Table 1 (continued)

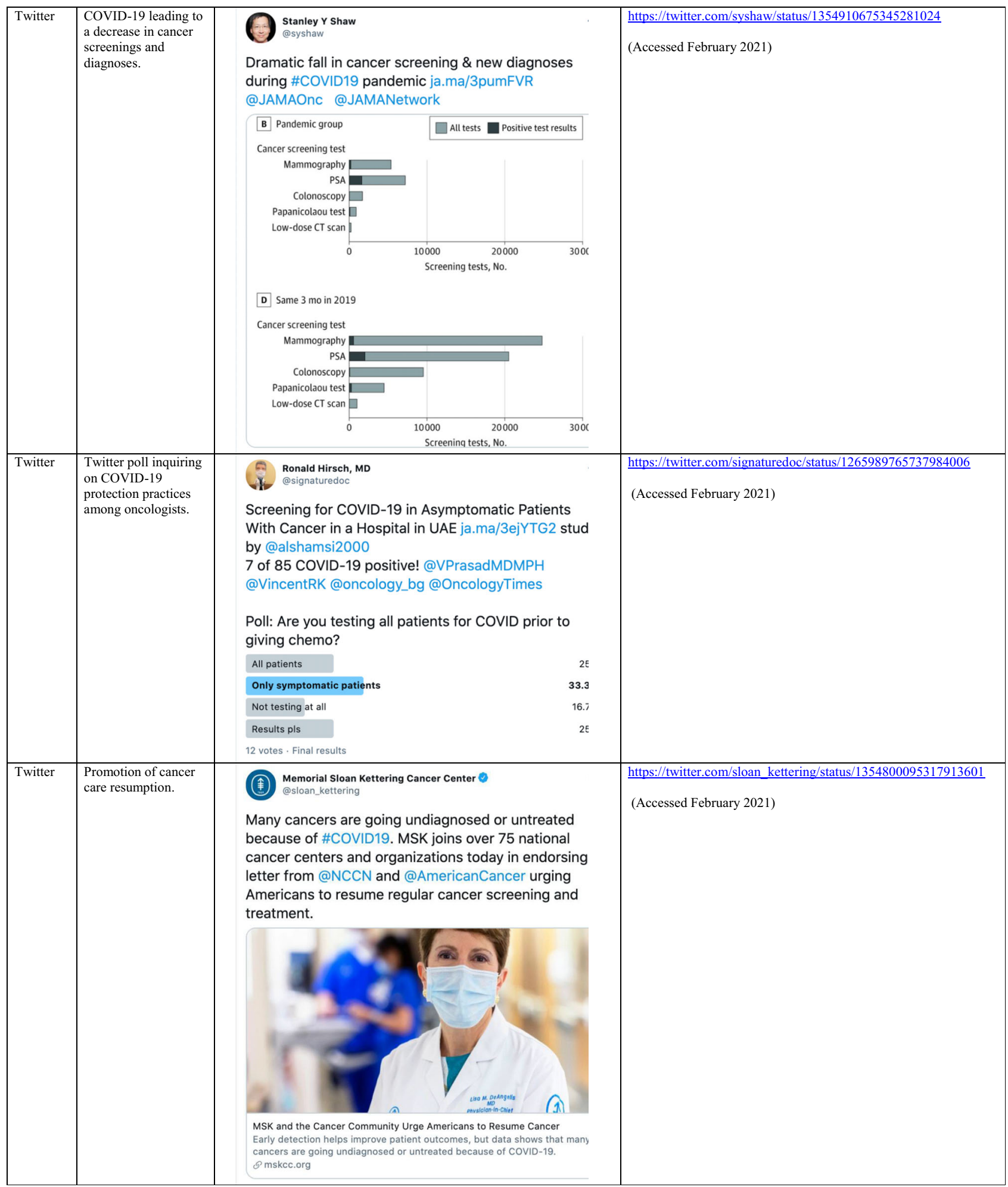

In addition to creating community and providing education, SoMe has been instrumental in catalyzing collaboration. Using SoMe platforms, healthcare care workers can connect quickly and globally, thus adhering to social distancing measures that have resulted in the cancellation of conferences, closures of universities, and the institution of remote work [32]. Given the growing use of SoMe platforms, these connections have facilitated more opportunities for career development, 
Table 1 (continued)

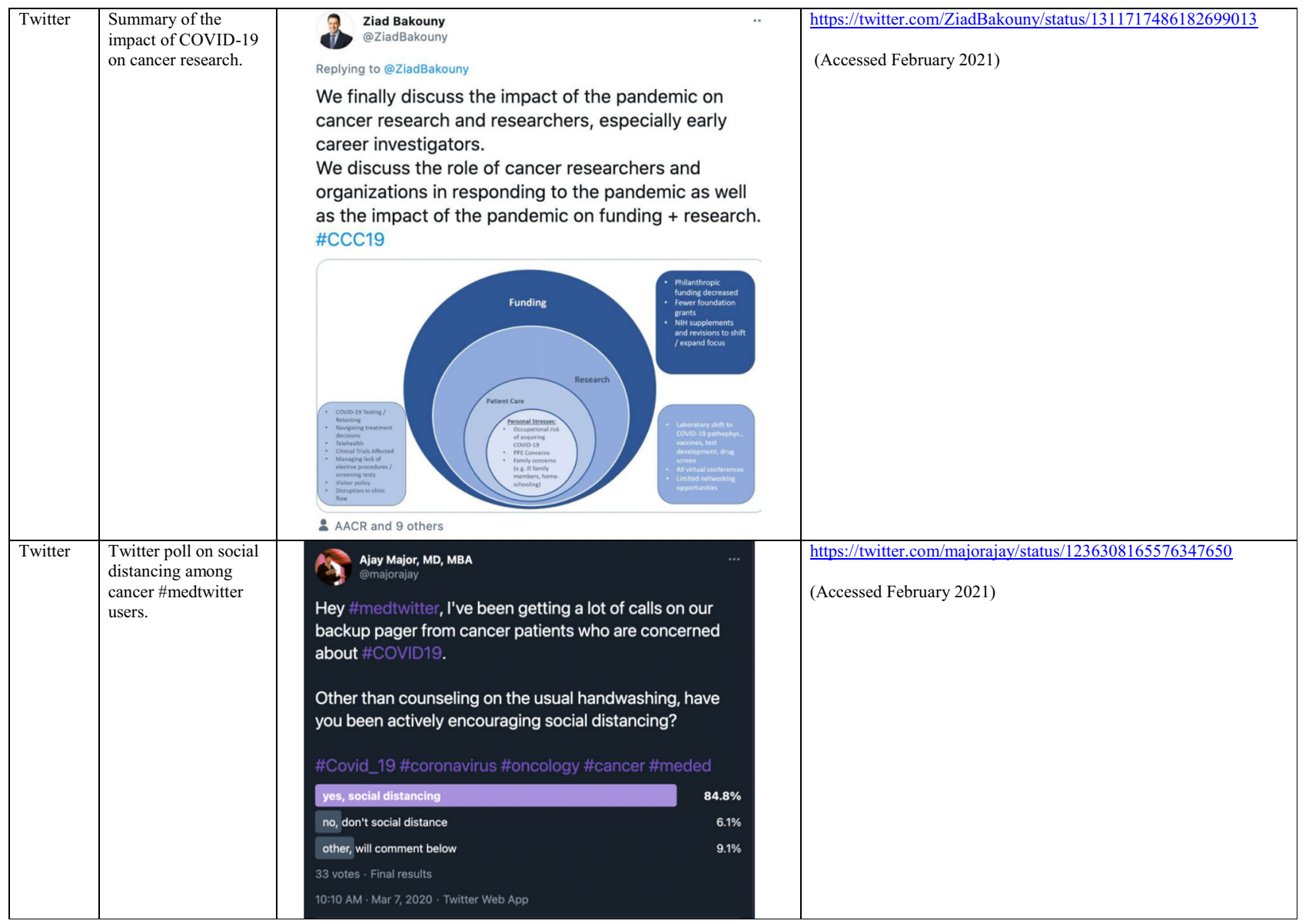

mentoring of physicians and physician scientists who are interested in cardio-oncology, and recruitment of participants in research studies on COVID-19 [37, 38]. Lastly, SoMe has been critical in providing physicians and other healthcare workers with a medium to advocate for themselves, particularly for increased PPE, and for the care of their patients (Fig. 1A). This is especially critical for physicians and healthcare workers treating cardio-oncologic patients as they may be immunocompromised and need further protection from COVID-19 infection. SoMe also allowed for rapid dissemination of daily clinical management decisions and provided a voice advocating against disparities in COVID-19 outcomes. Furthermore, the need to address patient care while promoting social distancing drove the need for telemedicine, and SoMe enabled sharing of best practices.

\section{The Rise of \#TelemedNow}

\#TelemedNow was born out of need. In the midst of the COVID-19 pandemic, a decade's worth of telemedicine preparative work was unleashed, enabled by the Centers for Medicare and Medicaid Services (CMS) approval of the use of telemedicine, with the release of new payment models and relaxed rules and regulations. These changes have allowed Americans to access medical care without incurring additional risk of contracting COVID-19. Because of the pressing need to share information about telemedicine, a team spearheaded by a cardiologist was coalesced in March 2020 to begin a missionminded weekly Twitter Chat with the hashtag \#TelemedNow. Symplur data show the growth of \#TelemedNow. Since its creation on March 18, 2020, the dissemination and support of \#TelemedNow grew in 3 months to almost one billion impressions and has continued to grow since then (Table 2).

The weekly Twitter Chat familiarizes healthcare providers, patients, advocacy groups, technology, and business leaders with various Telemedicine topics. Several chats have focused on health equity and shining a light on disparities in care by amplifying related articles. For example, the Social Vulnerability Index (SVI), created and maintained by@CDCgov, was highlighted, along with its association with COVID-19 case fatality rates and incidence. Researchers have used the SVI to delve into publicly available data and unearth troubling nationwide trends in racial and socioeconomic disparities in \#COVID-19 outcomes [39]. 


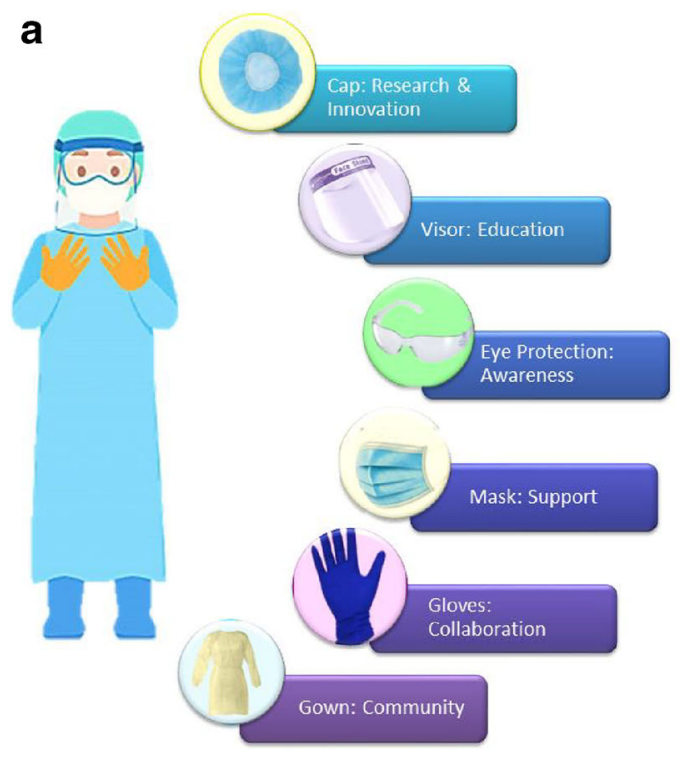

Fig. 1 Social media in the pandemic and care of cardio-oncology patients. A Personal protective equipment (\#PPE): cap, visor with face shield, googles, mask, gloves, and gown, each representing a component of the utility of social media pre-pandemic, during the pandemic, and post-pandemic. Overall, the image of \#PPE has in part come to be associated with advocacy for obtaining appropriate \#PPE and for adequately addressing health disparities. The cap represents research

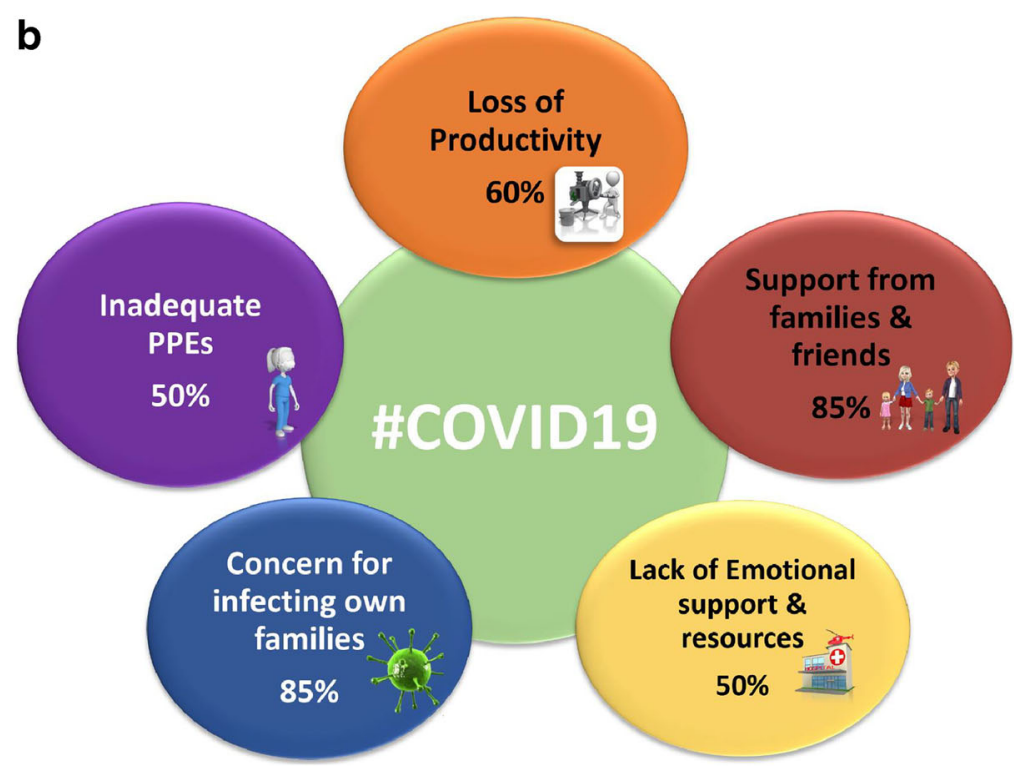

and innovation; the visor with face shield represents seeing new things and being educated during the pandemic (head, mind, brain); the goggles represent raising awareness and becoming more aware (seeing is believing); the mask represents support and protecting others and ourselves; the gloves represent collaboration; and the gown represents being able to identify each other in community. B Cardiology survey results
\#TelemedNow has also engaged the authors of papers on health equity, such as Jorge Rodriguez who has authored "Digital Health Equity as a Necessity in the $21^{\text {st }}$ Century Cures Act Era" [40]. Additionally, access to telehealth visits has been highlighted in a study from the University of Pennsylvania on their Outpatient Cardiovascular Care during the COVID-19 Pandemic. This study was discussed with the authors during the Twitter Chat [41]. Several \#TelemedNow chats have been devoted to leveling the playing field, to help close healthcare inequities. These threads and discussions have included CMS, as depicted in Table 2.

Although telehealth has traditionally been used in cardiology for the monitoring of rhythm, blood pressure, and heart failure exacerbations, cardio-oncology telehealth clinics have arisen in large part due to necessity in the pandemic. These telehealth clinics monitor the heart health of hematology/oncology patients who are undergoing or have completed cardiotoxic chemotherapy, with a focus on prevention and treatment. Telehealth has enabled the continuity of care for cardio-oncology patients who may have otherwise chosen to avoid receiving healthcare due to concern for COVID-19 infection. The rise of telehealth use in cardio-oncology presents an opportunity to assess its role and impact in the care and outcomes of cardiooncology patients in an evidence-based approach that will likely last beyond the pandemic [13, 42, 43].

\section{The Rise of the \#SOMECARDIOONC PHYSICIAN VOICE}

\section{COVID-19 Survey of Providers of Cardio-oncology Care}

The COVID-19 pandemic has turned hospitals into battlegrounds and doctors into soldiers. The lack of adequate personal protective equipment (PPE), the fear of infecting their own families, the shortage of ventilators, and the moral distress of having to navigate complex resource allocation decisions have created concerns among healthcare professionals. This moral dilemma and stress have paved the way for active dialogue on SoMe platforms including Twitter, Instagram, and Facebook [44].

In 2019, the World Health Organization expanded the definition of burnout from a state of exhaustion to a "syndrome resulting from chronic workplace stress." Physician burnout was already a public health crisis that affected almost half of physicians in the USA prior to COVID-19, according to Medscape surveys [41, 42].

To gauge the impact of COVID-19 pandemic on burnout, a team of cardiologists, including providers for cardiooncology patients, surveyed healthcare professionals in midApril 2020 via the SurveyMonkey platform [45]. The survey assessed perceived support from healthcare systems, concerns regarding PPE availability, impact on productivity, fear of 
Table 2 Care of COVID-19 patients and Leveraging Virtual Platforms

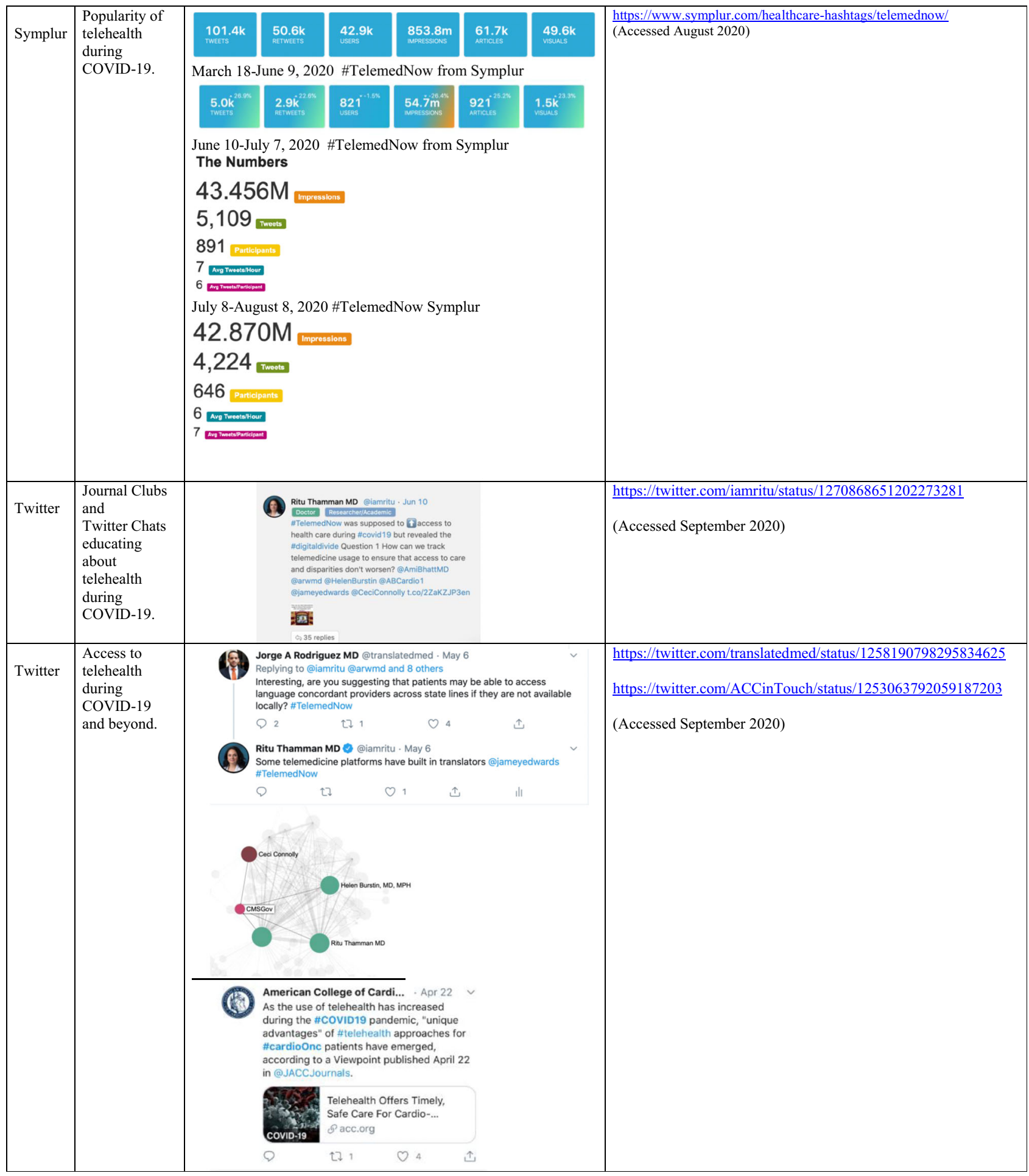

potential job loss, anxiety about spreading illness to immediate family members, and psychosocial resources at work and at home (Table 3). Out of the 553 responses received, 66\% were from physicians and the remainder were from nurses 
and allied practice providers. Women comprised $68 \%$ of those who responded. The concern about spreading infection to their own households was the most significant stressor according to $85 \%$ of all respondents. Among all the respondents, nearly $50 \%$ reported inadequate PPE, despite the fact that the survey was not limited to hot spot regions. Approximately 50\% of respondents had concerns about inadequate emotional support and resources from leadership in handling work-related issues. Almost $60 \%$ of responding physicians felt the pressure of loss of productivity. One positive finding was that $85 \%$ expressed having excellent family and friend support (Fig. 1B).

Another survey by the same group was conducted via SoMe (Twitter) to assess the impact of COVID-19 on cardiac electrophysiologists and their staff [46]. Out of the 241 respondents, $51 \%$ were physicians and $20 \%$ were nurses. About $60 \%$ of the respondents were women. The practice settings included private practice, academic positions, and hospital employment. Major concerns that were reported include fear of spreading the virus to the family members, inadequate PPE, and inability to perform elective cases due to lack of standardized testing and resources (Table 3).

\section{COVID-19 Physician Scientists Survey}

Physician scientists can play a key role in the evolution and resolution of the pandemic, as well as the advancement of cardio-oncology through research. Thus, assessment of the effect of the COVID-19 pandemic on this biomedical workforce is important [47]. A survey targeting this cohort, from trainees to faculty, leveraged SoMe platforms such as Twitter, Facebook, and LinkedIn to help raise awareness of the survey and increase response rates (Table 3) [48]. Leaders of the American Physician Scientists Association (APSA) developed the survey to include issues such as social isolation and the need to take care of children, as well as research activities and perceptions on productivity and patient care. The survey was distributed nationally to institutions with $\mathrm{MD} / \mathrm{PhD}$ programs with the help of the Association of American Medical Colleges (AAMC) Graduate Research, Education, and Training (GREAT) group and via APSA's Institutional representatives.

The survey garnered $>2100$ responses from around the country from medical students, graduate students, residents, fellows, and faculty. The survey found high levels of stress across all training stages, with perceived detriment to research productivity in the short and long terms due to COVID-19. Five percent of respondents were in cardiology and close to $10 \%$ were in hematology/oncology. These are physicians and physician scientists involved in the care of cardio-oncology patients as well as moving research insights forward. On platforms such as Twitter, this garnered attention and highlighted the vulnerability of female physician scientists, who in particular have already been shown to have a reduction in first and corresponding author publications during the pandemic [49]. SoMe facilitated discussions regarding the need to address these challenges and helped raise awareness [50]. Women were more likely to voice that they were under a great amount of stress and that this stress was shown to adversely affect their academic productivity.

Institutional leaders and foundations are recognizing these challenges faced by our physician scientists and have responded with providing funds to support those with high caregiving needs, as well as creating supportive programs to deal with stress [51, 52].

As the endangered phenomenon of physician scientists is a challenge and potential threat to human health, we must shine a light on the role of SoMe in helping physician and physician scientist careers within cardiology and oncology. SoMe has given physicians and physician scientists a voice and has also helped with career development in cardio-oncology, serving as a platform to raise visibility for our work, and this growing importance of SoMe has led universities to include SoMe scholarship as part of their metrics for promotion [53-57]. In fact, while citations and publications are traditional metrics for academic promotion in tenure tracks, SoMe has been shown to help increase citations [58-61]. In a study randomizing some articles to SoMe promotion compared to articles with no SoMe promotion, SoMe promotion increased article dissemination by fourfold [62]. Further, at scientific and medical meetings, which provide another venue to help with career visibility, SoMe can help facilitate sharing of work in its early stages, which can foster collaborations and networking in cardio-oncology, as well as assist with further dissemination of content [63-68].

\section{COVID-19 Cardio-oncology Survey}

A Cardio-oncology International Collaborative Network conducted an international survey via SurveyMonkey to assess the impact of the COVID-19 pandemic during its initial phase in March and April 2020 on the practices of cardiologists and oncologists; the effects of the pandemic on re-allocation of resources for elective procedures, testing, scheduling, and access to telemedicine services; the early utilization of new COVID-19 therapies; and providers' opinions on national healthcare policies [69]. Approximately 1500 providers from 43 countries responded to this survey, which provided new data on the similarities and differences experienced by physicians in different geographic locations and the impact of this pandemic on both academic-based practices and private practice settings [70].

The use of electronic platforms and SoMe allowed for promotion, enrollment, and amplification of the response to this survey by providing a heterogeneous target audience practicing in various geographic locations. There was participation of 
Table 3 Pulse of Health Care Professionals Taking Care of Cardio-Oncology Patients.

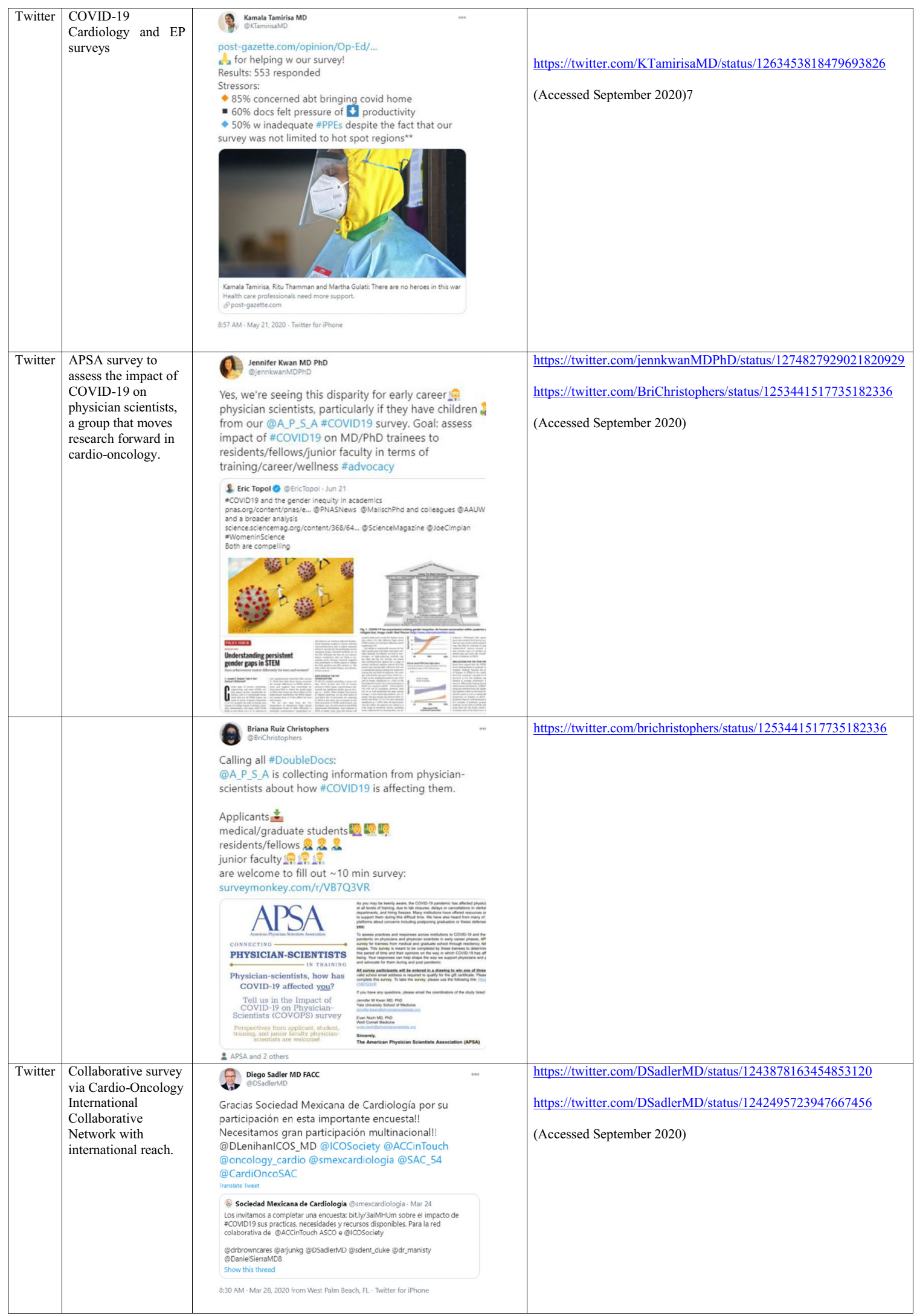


Table 3 (continued)

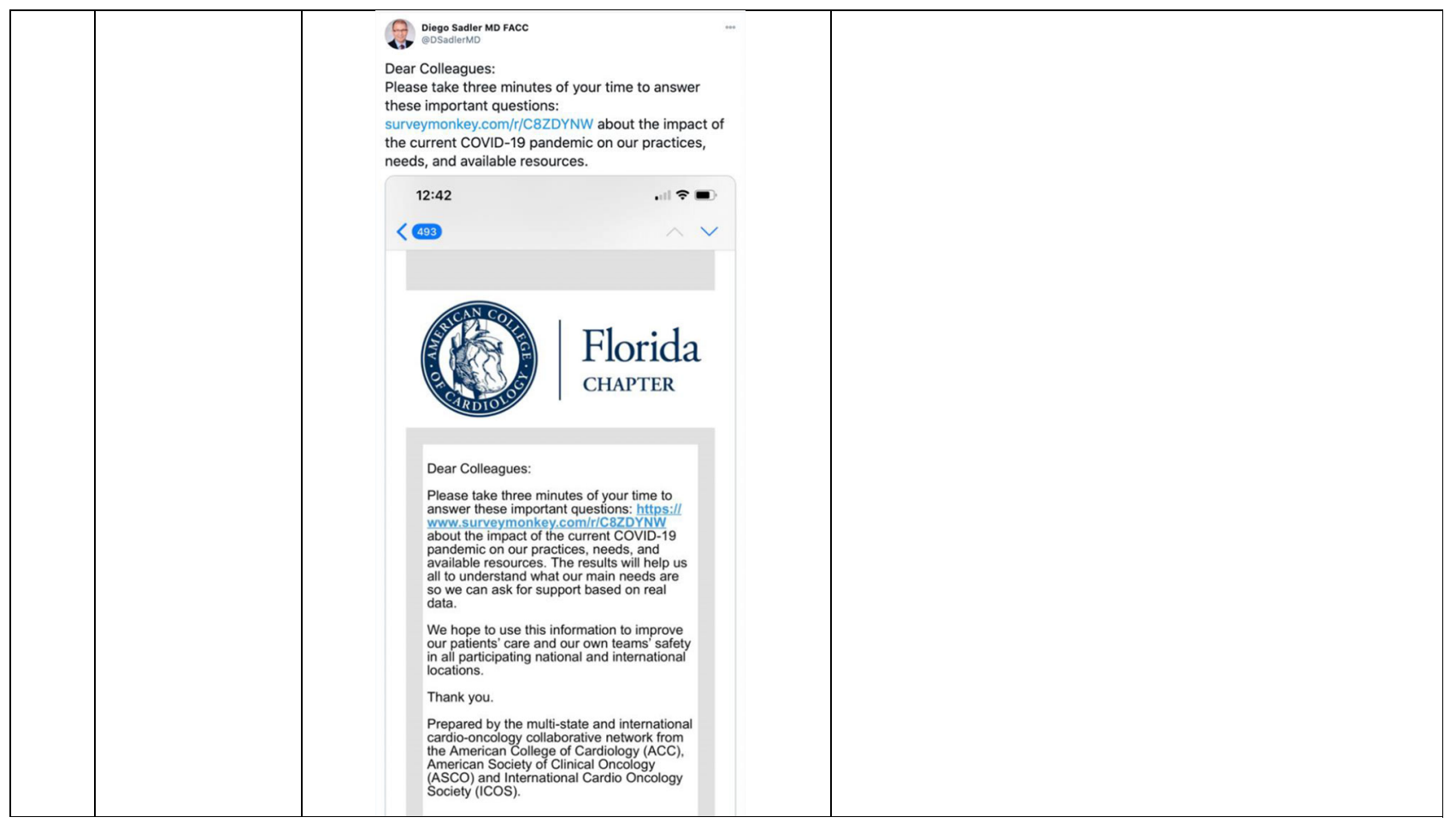

members from state chapters from the American College of Cardiology (ACC) and the American Society of Clinical Oncology (ASCO) and regional chapters from the International Cardio-Oncology Society (ICOS). The use of SoMe, particularly Twitter, improved the visibility of our invitation to physicians to participate in this survey. Some participating sites, such as the Florida Chapter of the ACC, the Illinois Chapter of the ACC, and the Sociedad Mexicana de Cardiologia, among others, utilized the Twitter platform to promote this survey among members and local practicing physicians, thus increasing physician engagement (Table 3).

\section{The Rise of \#HEALTHDISPARITIES}

COVID-19 has shed a light on the various health disparities that have long affected vulnerable groups [71, 72]. Cardiac disease and cancer, among others, are of high concern for patients who may be infected. Some authors have pointed to the vulnerability of those who are not able to undergo screening exams pertinent to their age and sex, such as for breast, prostate, or colon cancer [73]. The number of missed diagnoses has been estimated at 80,000 during the first 3 months of the pandemic [74]. This number has likely grown as the pandemic has continued. A delayed diagnosis can be harmful. A recent study showed that each 4-week delay in cancer treatment increased cancer mortality by $10 \%$ [75]. The American Association for Cancer
Research virtual meeting featured a dedicated session on the impact of health inequities and disparities caused by the pandemic on cancer care, recognizing the need to prevent and treat COVID-19 and address quality health access overall —not limited to the pandemic [76].

Health disparities between non-white individuals and their white counterparts have been well documented across medical subspecialties long before COVID-19 emerged [77-80]. As more states release sociodemographic data, the disproportionate morbidity and mortality for Black and Latino patients associated with COVID-19 has made these pre-existing disparities even clearer [36]. Once data have become public, the popular press and academic journals have been publishing pieces calling for action to change the course to protect people of color, specifically by addressing the structural inequalities that predispose ethnic minorities to developing comorbidities [81-83].

On Twitter, National Public Radio sounded the alarm in April 2020 about the risk for racial minorities with heart disease to be disproportionately exposed to COVID-19 infection $[84,85]$. Circulation journal published a commentary by representatives of the Association of Black Cardiologists that likens the broad causes of COVID-19 health disparities to those that lead to higher comorbidities in everyday life, including discrimination and lack of access to care $[86,87]$. Data from New York City about the high COVID-19 mortality rates seen for Black and Latino patients is similar to mortality rates from breast cancer for 
these groups [88]. Those living in regions of worse air quality near chemical plants and other manufacturers, associated with increased risk for developing cancer, also appear to be at higher risk for COVID-19, which links environmental racism with cancer and infectious disease [89, 90]. A webinar offered as part of the \#EmPOWERChange SoMe campaign educated healthcare professionals about the risk that cardiac comorbidities pose for Latino communities during the pandemic [91]. Table 4 shows examples in which SoMe shed light on health disparities and pushed for equality and health equity. SoMe has played an important role in amplifying the magnitude of the impact of COVID-19 on cancer care and patients from minority groups, and we hope this will motivate health professionals to use this knowledge and opportunity to make broader change. SoMe may also be used to promote vaccination in these groups, to answer questions these patients may have about the vaccine, and to push for access for equity in the distribution of vaccines. Table 4 shows several tweets in which individuals have pushed for increased access to vaccines among African American and Latino populations who have been disproportionately impacted by the pandemic.

\section{Discussion}

As the number of COVID-19 patients continues to rise around the world and in the USA, short- and long-term health sequelae will be a major challenge for healthcare providers in cardiooncology and the rest of society due to lost productivity, increased costs, and impaired quality of life. Dealing with challenges that arise and finding effective solutions in the pandemic will continue to require collective efforts from healthcare professionals, policy makers, patients, and society. SoMe has the power to connect all of us and facilitate education, behavioral changes, and research. We have seen healthcare professionals and patients embrace SoMe to help educate and advocate, and SoMe has facilitated research on the effects of the pandemic on healthcare workers, patients, and healthcare systems [92-94].

The need to "flatten the curve" has arisen as a persistent challenge in the pandemic to deal with limited hospital resources and PPE. This has included reducing patient visits and non-urgent procedures. To keep up with patient care, telemedicine, which was already routinely being used in more remote settings, stepped in to provide virtual patient care. SoMe was used to raise awareness of telemedicine and exchange information about best practices. SoMe was also used to highlight the importance of determining outcomes associated with telemedicine-mediated healthcare and the need for research to determine which patients would benefit versus those who should be seen in person.
While the potential as a research tool has been demonstrated, more safeguards may be needed to ensure surveys disseminated via SoMe channels are reaching the intended target audience and that responses are from the target audience. SoMe can also effectively disseminate research information, such as for COVID-19 and cardio-oncology. Early on in the pandemic, the healthcare community was grasping to obtain information related to COVID-19 infection, including which populations are more vulnerable and likely to have a worse outcome, and what treatments are effective for the novel virus that seems to spread and kill at a higher rate than the flu. Research from China, the initial infection hotspot, identified cohorts that were more vulnerable and had worse outcomes. These included those with underlying heart disease as well as those with cancer, particularly metastatic disease. This information reached those at risk and healthcare providers in part via SoMe channels, to encourage these patients to be more cautious. This helped guide US healthcare providers evaluating various therapies. For cardio-oncology patients, some cancer treatment and screenings were postponed during initial lockdowns, and SoMe served as a way to educate patients about when to seek medical attention.

The COVID-19 pandemic has exacerbated pre-existing health and financial disparities, which have afflicted underrepresented minorities for centuries $[83,95,96]$. This has been the case within cardiovascular medicine and oncology. SoMe has helped to highlight studies that have provided these insights and has played a major role in advocacy to address these disparities. Thus, advocacy from all fronts and support from the highest levels of government, as well as all echelons of society, including institutional support will be needed to safeguard these vulnerable populations. Mining SoMe data and evaluating mobile health platform data and electronic health records using artificial intelligence (AI) may provide us insights on ways to help improve health disparities during the pandemic and beyond [97-102]. At the same time, we must ensure that datasets used to train AI algorithms appropriately represent patient diversity, so that health disparities can be curbed instead of exacerbated by use of these powerful informatics tools [103]. Specific to cardio-oncology, AI may also be used in combination with ECGs to detect atrial fibrillation and predict cardiomyopathy. In addition, for various potentially cardiotoxic oncologic therapies including CAR-T therapy, AI may also be used to elucidate risk factors for adverse outcomes due to these therapies.

In some ways, physician scientists have been jeopardized by this pandemic in terms of their ability to apply their training and skills to tackling disease. Many physician scientists, including those who care for cardio-oncology patients, have expressed high levels of stress and decreased research productivity during the pandemic. Continuation of some kinds of research has been threatened due to institutional hiring freezes, as a result of financial hits to healthcare systems. 
Table 4 Health Disparities in the Context of COVID-19 and Cardio-Oncology

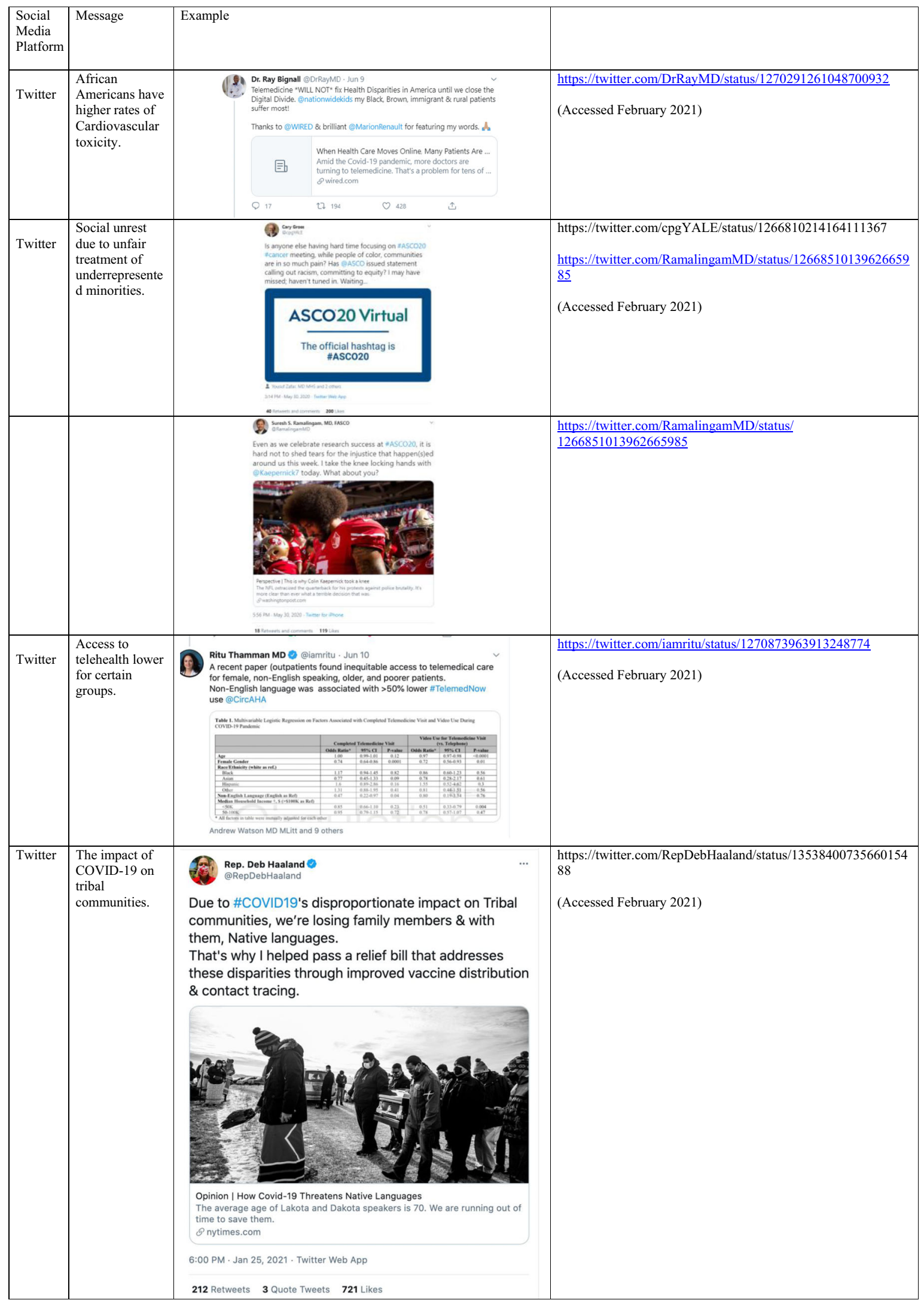

See online collage: \#COVID-19 \#Cardiooncology SoMe Collection capturing the pulse of the COVID-19 pandemic http://cardiooncology.s3-websiteus-west-2.amazonaws.com/ (107) 
Table 4 (continued)

\begin{tabular}{|c|c|c|c|c|c|}
\hline \multirow[t]{3}{*}{ Twitter } & \multirow[t]{3}{*}{$\begin{array}{l}\text { Encouraging for } \\
\text { the vaccination } \\
\text { of diverse } \\
\text { groups impacted } \\
\text { by the pandemic. }\end{array}$} & \multicolumn{3}{|c|}{$\begin{array}{l}\text { Elizabeth Warren } \\
\text { @SenWarren } \\
\text { Black, Latino, Indigenous, \& immigrant communities hi } \\
\text { hardest by COVID-19 need equitable access to } \\
\text { vaccines. @RepPressley, @SenMarkey \& I are urging } \\
\text { @HHSgov to publish racial, ethnic \& demographic dat: } \\
\text { on vaccine recipients so we can address disparities. }\end{array}$} & \multirow[t]{3}{*}{$\begin{array}{l}\text { https://twitter.com/SenWarren/status/1354944545750986759 } \\
\text { (Accessed February 2021) }\end{array}$} \\
\hline & & 国 & $\begin{array}{l}\text { Democratic lawn } \\
\text { Democratic lawn } \\
\text { address racial di. } \\
\text { @apnews.com }\end{array}$ & $\begin{array}{l}\text { data in vaccinations } \\
\text { deral health officials to } \\
\text { ccess nationwide, as ... }\end{array}$ & \\
\hline & & \multicolumn{3}{|c|}{ 7:08 PM · Jan 28, 2021 - Twitter Web App } & \\
\hline \multirow[t]{3}{*}{ Twitter } & \multirow[t]{3}{*}{$\begin{array}{l}\text { Information on } \\
\text { how COVID-19 } \\
\text { has furthered } \\
\text { cancer } \\
\text { disparities. }\end{array}$} & \multicolumn{3}{|c|}{$\begin{array}{l}\text { FAA FDA Oncology } \\
\text { DispaOnarities in Cancer Prevention in the \#COVID19 Era. } \\
\text { Pandemic could leave underserved populations further } \\
\text { behind in cancer screening. John Carethers, Rajarshi } \\
\text { Sengupta, \#FDAOncology @rea_blakey, @AACRPres } \\
\text { Antoni Ribas \& Gypsyamber D'Souza @CAPR_AACR } \\
\text { bit.ly/3mzLQp0 }\end{array}$} & \multirow[t]{3}{*}{$\begin{array}{l}\text { https://twitter.com/FDAOncology/status/130875425805404569 } \\
\underline{7} \\
\text { (Accessed February 2021) }\end{array}$} \\
\hline & & \multicolumn{3}{|c|}{ 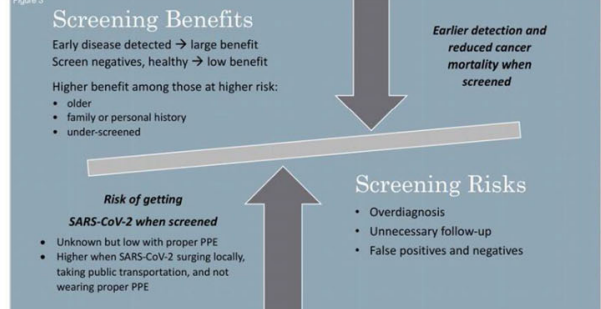 } & \\
\hline & & 9:05 AM - Ser & 2020 . Hootsuite & & \\
\hline \multirow[t]{3}{*}{ Twitter } & \multirow[t]{3}{*}{$\begin{array}{l}\text { Highlighting } \\
\text { how } \\
\text { telemedicine } \\
\text { can impact rural } \\
\text { populations. }\end{array}$} & \multicolumn{3}{|c|}{$\begin{array}{l}\text { Js } \\
\text { Teleoncologrinilason policies can be critical tools for } \\
\text { mitigating rural cancer disparities, but also preventing } \\
\text { delays in cancer screening and treatment from covid- } \\
19 \text { restrictions. \#ruralhealth \#cancer \#telehealth } \\
\text { \#medicaid \#covid19 }\end{array}$} & \multirow[t]{3}{*}{$\begin{array}{l}\text { https://twitter.com/SempriniJason/status/1268552699726962688 } \\
\text { (Accessed February 2021) }\end{array}$} \\
\hline & & 目 & $\begin{array}{l}\text { Expanding the } C \\
\text { Background: I } t \\
\text { causes of death } \\
\text { \& newprairiepre: }\end{array}$ & $\begin{array}{l}\text { cer Care With Teleo.... } \\
\text { col the } 2 \text { leading } \\
\text { fic cancers, resultin... }\end{array}$ & \\
\hline & & \multicolumn{3}{|c|}{ 10:38 AM . Jun 4, 2020 - Twitter Web App } & \\
\hline
\end{tabular}

However, it is important to recognize the importance of supporting the biomedical workforce through the pandemic, "to help us develop effective solutions in this current pandemic and future pandemics, and advance research to improve outcomes for patients in cardio-oncology.

While SoMe has a myriad of benefits, there can be limitations. It is crucial to ensure the accuracy of information posted on SoMe platforms, particularly for scientific and health information [104]. Advocacy for SoMe platforms to counter and report misinformation will be crucial now and in decades to come as more individuals use SoMe platforms as sources of trusted information.
Given that SoMe is an important and increasingly used tool, the medical profession should adhere to professional standards for respect and protection of patients, with the goals of collaboration, education, and advocacy. There should be increased training during medical education on how to harness SoMe as a tool to improve clinical care, research, and medical care related to COVID-19 and cardio-oncology [105]. In summary, SoMe has successfully helped with education and career development and promotion and has served as a platform and data source for research for cardio-oncology and other areas of medicine in the pandemic. 


\section{Conclusions}

The importance of SoMe in public health and medicine has become more pronounced during the COVID-19 pandemic. In cardio-oncology, SoMe has fostered education, outreach, awareness, collaboration, dissemination of information, and advocacy. SoMe has also been critical in uniting the fields of cardiology and hematology/oncology so that physicians may navigate the obstacles that the pandemic has placed on patient care. More broadly, during the pandemic, SoMe has also supported patient care innovation, particularly, telemedicine, the amplification of healthcare workers' voices, and the illumination of pre-existing and continued health disparities. Other advantages of SoMe have included the ability to disseminate a message rapidly and globally, with minimal resources. Future research should monitor the utility and impact of social media among physicians during the pandemic and beyond. Furthermore, healthcare professionals, including those in cardio-oncology, may benefit from increased training on how to harness SoMe to support their efforts in clinical care, education, research, and advocacy.

Acknowledgements We are grateful to Andrew Choi for the helpful feedback on this review and to Mark Lu, Tony Joodi, and Katie Hogan for the help with creating the online SoMe post compilation; as well as to Eric Topol, Ray Bignall, Suresh Ramalingham, Cary Gross, European Society of Cardiology, American College of Cardiology, Naveen Pemmaraju, Jorge Rodriguez, Amy Moore, Stanley Shaw, Ronald Hirsch, MKSCC, and Sapna Kudchadkar for the permission to share their SoME posts and finally to all authors of SoME posts featured in this review.

\section{Declarations}

Conflict of Interest None of the authors has any potential conflicts of interest to disclose.

Human and Animal Rights and Informed Consent This article does not contain any studies with human or animal subjects performed by any of the authors.

\section{References}

1. Mehta LS, Watson KE, Barac A, Beckie TM, Bittner V, CruzFlores $\mathrm{S}$, et al. Cardiovascular disease and breast cancer: where these entities intersect: a scientific statement from the American Heart Association. Circulation. 2018;137(8):e30-66.

2. Brown S-A, Daly RP, Duma N, Yang EH, Pemmaraju N, Parwani $\mathrm{P}$, et al. Leveraging social media for cardio-oncology. Curr Treat Options in Oncol. 2020;21(10):1-19.

3. Parwani P, Choi AD, Lopez-Mattei J, Raza S, Chen T, Narang A, et al. Understanding social media: opportunities for cardiovascular medicine. J Am Coll Cardiol. 2019;73(9):1089-93.

4. Mandrola J, Futyma P. The role of social media in cardiology. Trends Cardiovasc Med. 2020;30(1):32-5.
5. Schumacher KR, Lee JM, Pasquali SK. Social media in paediatric heart disease: professional use and opportunities to improve cardiac care. Cardiol Young. 2015;25(8):1584-9.

6. Rosselló X, Stanbury M, Beeri R, Kirchhof P, Casadei B, Kotecha D. Digital learning and the future cardiologist. Eur Heart J. 2019;40(6):499-501.

7. Walsh MN. Social Media and Cardiology. J Am Coll Cardiol. 2018;71(9):1044-7.

8. Cifu AS, Vandross AL, Prasad V. Case Reports in the Age of Twitter. Am J Med. 2019;132(10):e725-e6.

9. Kuehn BM. Social media becomes a growing force in cardiology. Circulation. 2019;140(9):790-2.

10. Redfern J, Ingles J, Neubeck L, Johnston S, Semsarian C. Tweeting our way to cardiovascular health. J Am Coll Cardiol. 2013;61(15):1657-8.

11. Campbell L, Evans Y, Pumper M, Moreno MA. Social media use by physicians: a qualitative study of the new frontier of medicine. BMC Med Inform Decis Mak. 2016;16:91.

12. Yeh RW. Academic cardiology and social media: navigating the wisdom and madness of the crowd. Circ Cardiovasc Qual Outcomes. 2018;11(4):e004736.

13. Brown S-A, Rhee J-W, Guha A, Rao VU. Innovation in precision cardio-oncology during the coronavirus pandemic and into a postpandemic world. Front Cardiovasc Med. 2020;7:145.

14. Eichstaedt JC, Smith RJ, Merchant RM, Ungar LH, Crutchley P, Preoțiuc-Pietro D, et al. Facebook language predicts depression in medical records. Proc Natl Acad Sci. 2018;115(44):11203.

15. Reece AG, Danforth CM. Instagram photos reveal predictive markers of depression. EPJ Data Science. 2017;6(1):15.

16. Conley CC, Goyal NG, Brown SA. \#CardioOncology: Twitter chat as a mechanism for increasing awareness of heart health for cancer patients. 2020;6:19-Cardiooncology.

17. Aggarwal NR, Alasnag M, Mamas MA. Social media in the era of COVID-19. Open heart. 2020;7(2).

18. Organization WH. Coronavirus disease (COVID-19) Situation Report - 162. 2020.

19. Guan WJ, Ni ZY, Hu Y, Liang WH, Ou CQ, He JX, et al. Clinical characteristics of coronavirus disease 2019 in China. N Engl J Med. 2020;382(18):1708-20.

20. Shi S, Qin M, Shen B, Cai Y, Liu T, Yang F, et al. Association of cardiac injury with mortality in hospitalized patients with COVID19 in Wuhan China. JAMA Cardiol. 2020;5(7):802-10.

21. Guo T, Fan Y, Chen M, Wu X, Zhang L, He T, et al. Cardiovascular implications of fatal outcomes of patients with coronavirus disease 2019 (COVID-19). JAMA Cardiol. 2020;5(7):811-8.

22. Madjid M, Safavi-Naeini P, Solomon SD, Vardeny O. Potential effects of coronaviruses on the cardiovascular system: a review. JAMA Cardiol. 2020;5(7):831-40.

23. Lee LY, Cazier JB, Starkey T, Turnbull C, Team UCCMP, Kerr $\mathrm{R}$, et al. COVID-19 mortality in patients with cancer on chemotherapy or other anticancer treatments: a prospective cohort study. The Lancet. 2020

24. Lee LY, Cazier J-B, Starkey T, Briggs SE, Arnold R, Bisht V, et al. COVID-19 prevalence and mortality in patients with cancer and the effect of primary tumour subtype and patient demographics: a prospective cohort study. The Lancet Oncology. 2020;21(10):1309-16.

25. Dai M, Liu D, Liu M, Zhou F, Li G, Chen Z, et al. Patients with cancer appear more vulnerable to SARS-COV-2: a multicenter study during the COVID-19 outbreak. Cancer discovery. 2020;10(6):783-91.

26. Navi BB, Reiner AS, Kamel H, Iadecola C, Okin PM, Elkind MSV, et al. Risk of arterial thromboembolism in patients with cancer. J Am Coll Cardiol. 2017;70(8):926-38. 
27. Inohara T, Endo A, Melloni C. Unmet needs in managing myocardial infarction in patients with malignancy. Front Cardiovasc Med. 2019;6:57.

28. Drobni ZD, Alvi RM, Taron J, Zafar A, Murphy SP, Rambarat PK, et al. Association between immune checkpoint inhibitors with cardiovascular events and atherosclerotic plaque. Circulation. 2020;142(24):2299-311.

29. Fornell D. CMS calls for postponing all elective cardiac tests and procedures to aid COVID-19 Containment Diagnostic and Interventional Cardiology 2020 [Available from: https://www. dicardiology.com/article/cms-calls-postponing-all-electivecardiac-tests-and-procedures-aid-covid-19-containment.

30. Zitelny E, Newman N, Zhao D. STEMI during the COVID-19 pandemic-an evaluation of incidence: Elsevier; 2020.

31. Lwin MO, Lu J, Sheldenkar A, Schulz PJ, Shin W, Gupta R, et al. Global sentiments surrounding the COVID-19 pandemic on Twitter: analysis of Twitter trends. JMIR Public Health Surveill. 2020;6(2):e19447.

32. Chen E, Lerman K, Ferrara E. Tracking social media discourse about the COVID-19 pandemic: development of a public coronavirus Twitter data set. JMIR Public Health Surveill. 2020;6(2): e19273.

33. Bhagavathula AS, Aldhaleei WA, Rahmani J, Mahabadi MA, Bandari DK. Knowledge and perceptions of COVID-19 among health care workers: cross-sectional study. JMIR Public Health Surveill. 2020;6(2):e19160.

34. Limaye RJ, Sauer M, Ali J, Bernstein J, Wahl B, Barnhill A, et al. Building trust while influencing online COVID-19 content in the social media world. The Lancet Digital Health. 2020;2(6):e277e8.

35. Basch CE, Basch CH, Hillyer GC, Jaime C. The role of YouTube and the entertainment industry in saving lives by educating and mobilizing the public to adopt behaviors for community mitigation of COVID-19: successive sampling design study. JMIR Public Health Surveill. 2020;6(2):e19145.

36. Webb Hooper M, Nápoles AM, Pérez-Stable EJ. COVID-19 and racial/ethnic disparities. JAMA. 2020.

37. Smith A. U.S. Smartphone Use in 2015 Pew Research Center 2015 [Available from: https://www.pewresearch.org/internet/ 2015/04/01/us-smartphone-use-in-2015/.

38. Shaban $\mathrm{H}$. Twitter reveals its daily active user numbers for the first time The Washington Post 2019 [Available from: https://www. washingtonpost.com/technology/2019/02/07/twitter-reveals-itsdaily-active-user-numbers-first-time/.

39. Nayak A, Islam SJ, Mehta A, Ko Y-A, Patel SA, Goyal A, et al. Impact of social vulnerability on COVID-19 incidence and outcomes in the United States. medRxiv. 2020.

40. Rodriguez JA, Clark CR, Bates DW. Digital health equity as a necessity in the 21 st century cures act era. JAMA. 2020.

41. Eberly LA, Khatana SAM, Nathan AS, Snider C, Julien HM, Deleener ME, et al. Telemedicine outpatient cardiovascular care during the COVID-19 pandemic: bridging or opening the digital divide? Circulation. 2020

42. Parikh A, Kumar AA, Jahangir E. Cardio-Oncology Care in the Time of COVID-19 and the Role of Telehealth. JACC: CardioOncology. 2020;2(2):356-8.

43. Lenihan D, Carver J, Porter C, Liu JE, Dent S, Thavendiranathan $\mathrm{P}$, et al. Cardio-oncology care in the era of the coronavirus disease 2019 (COVID-19) pandemic: an International Cardio-Oncology Society (ICOS) statement. CA Cancer J Clin. 2020.

44. Health NIo. COVID-19 Social media resources nih.govSeptember 2020 [Available from: https://www.nih.gov/news-events/covid19-social-media-resources.

45. Tamirisa K, Thamman R, Gulati M. There are no heroes in this war 2020 [Available from: https://www.post-gazette.com/ opinion/Op-Ed/2020/05/15/Kamala-Tamirisa-Ritu-Thamman-
Martha-Gulati-COVID-19-pandemic-no-heroes-war/stories/ 202005150036.

46. Tamirisa K. Impact of COVID-19 pandemic on the mental wellbeing of electrophysiology providers survey $<$ div arialabel="Important according to Google magic." class="pG" datatooltip-align="b,l" data-tooltip-contained="true" data-tooltip-delay="1500" id=":2jj" role="img" style="font-size: 0px; padding: 0px; position: relative; width: 20px; height: 20px; cursor: pointer; align-items: center; display: inline-block; justify-content: center; margin: 0px 8px 0px 0px;"> 2020 [Available from: https://www. surveymonkey.com/r/XLZVGFP.

47. Jain MK, Cheung VG, Utz PJ, Kobilka BK, Yamada T, Lefkowitz R. Saving the endangered physician-scientist - a plan for accelerating medical breakthroughs. N Engl J Med. 2019;381(5):399402.

48. Lucci-Canapari J. Survey Concludes Physician-scientists Need More Support. Yale School of Medicine, Department of Internal Medicine 2020 [Available from: https://medicine.yale.edu/ intmed/news-article/26488/.

49. Phillippe Vincent-Lamarre CRS, Vincent Lariviere. The decline of women's research production during the coronavirus pandemic. May 2020 [Available from: https://www.natureindex.com/newsblog/decline-women-scientist-research-publishing-productioncoronavirus-pandemic.

50.@MagazineYale. Recently, @Yale physician-scientist @ jennkwanMDPhD conducted a survey on how COVID-19 has impacted colleagues. @YaleMed August 2020 [Available from: https://twitter.com/MagazineYale/status/ 1291459498369060865.

51. COVID Gap Funding Yale School of Medicine 2020 [Available from: https://medicine.yale.edu/about/deanoffice/covid-gapfunding/.

52. Coping \& Well-being Yale University 2020 [Available from: https://covid.yale.edu/resources/wellbeing/.

53. Cabrera D. Using social media in academic promotion Mayo Clinic Social Media Network 2017 [Available from: https:/ socialmedia.mayoclinic.org/2017/08/16/using-social-media-inacademic-promotion/.

54. Chan TM, Stukus D, Leppink J, Duque L, Bigham BL, Mehta N, et al. Social media and the 21 st-century scholar: how you can harness social media to amplify your career. J Am Coll Radiol. 2018;15(1):142-8.

55. Cabrera D, Vartabedian BS, Spinner RJ, Jordan BL, Aase LA, Timimi FK. More than likes and tweets: creating social media portfolios for academic promotion and tenure. Journal of graduate medical education. 2017;9(4):421-5.

56. Cabrera D, Roy D, Chisolm MS. Social media scholarship and alternative metrics for academic promotion and tenure. J Am Coll Radiol. 2018;15(1):135-41.

57. Sherbino J, Arora VM, Van Melle E, Rogers R, Frank JR, Holmboe ES. Criteria for social media-based scholarship in health professions education. Postgrad Med J. 2015;91(1080):551-5.

58. Carpenter CR, Cone DC, Sarli CC. Using publication metrics to highlight academic productivity and research impact. Acad Emerg Med. 2014;21(10):1160-72.

59. Buckarma EH, Thiels CA, Gas BL, Cabrera D, Bingener-Casey J, Farley DR. Influence of social media on the dissemination of a traditional surgical research article. J Surg Educ. 2017;74(1):7983.

60. Eysenbach G. Can tweets predict citations? Metrics of social impact based on Twitter and correlation with traditional metrics of scientific impact. J Med Internet Res. 2011;13(4):e123.

61. Smith ZL, Chiang AL, Bowman D, Wallace MB. Longitudinal relationship between social media activity and article citations in the journal Gastrointestinal Endoscopy. Gastrointest Endosc. 2019;90(1):77-83. 
62. Widmer RJ, Mandrekar J, Ward A, Aase LA, Lanier WL, Timimi FK, et al. Effect of promotion via social media on access of articles in an academic medical journal: a randomized controlled trial. Academic Medicine. 2019;94(10).

63. Pemmaraju N, Mesa RA, Majhail NS, Thompson MA, editors. The use and impact of Twitter at medical conferences: best practices and Twitter etiquette. Seminars in hematology; 2017: Elsevier.

64. Pemmaraju N, Thompson MA, Mesa RA, Desai T. Analysis of the use and impact of Twitter during American Society of Clinical Oncology annual meetings from 2011 to 2016: focus on advanced metrics and user trends. Journal of oncology practice. 2017;13(7): e623-e31.

65. Gorodeski EZ. Make your mark at medical meetings with social media 2018 MEDPAGE Today 2018

66. Soreide K, Mackenzie G, Polom K, Lorenzon L, Mohan H, Mayol J. Tweeting the meeting: quantitative and qualitative twitter activity during the 38th ESSO conference. Eur J Surg Oncol. 2019;45(2):284-9.

67. Hudson S, Mackenzie G. 'Not your daughter's Facebook': Twitter use at the European Society of Cardiology Conference 2018. Heart. 2019;105(2):169-70.

68. Tanoue MT, Chatterjee D, Nguyen HL, Sekimura T, West BH, Elashoff D, et al. Tweeting the meeting: rapid growth in the use of social media at major cardiovascular scientific sessions from 2014 to 2016. Circulation: Cardiovascular Quality and Outcomes. 2018;11(11):e005018.

69. Sadler D. Cardio-Oncology International Collaborative Network survey. 2020.

70. Diego Sadler JMD, Joerg Herrmann, Anita Arnold, Arjun K. Ghosh, Husam Abdel-Qadir, Eric H. Yang, Sebastian SZmit, Nausheen Akhter, Monika Leja, Carolina Maria Pinto Domingues Carvalho Silva, Jayant Raikhelkar, Sherry-Ann Brown, Rupal O'Quinn, Franck Thuny, Rohit Moudgil, Luis M. Raez, Tochukwu Okwuosa, Andres Daniele, Brenton Bauer, Lavanya Kondapalli, Roohi Ismail-Khan, Jorge Lax, Anne Blaes, Zeina Nahleh, Leah Elson, Lauren Baldassarre, Vlad Zaha, Vijay Rao, Daniel Sierra Lara, Kerry Skurka, Susan Dent. The COVID-19 Pandemic Impact on Cardio-Oncology: Results From the COVID-19 International Collaborative Network Survey. Cardio-oncology BMC. 2020; Preprint.

71. Hoehn RS, Zureikat AH. Cancer disparities in the COVID-19 era. J Surg Oncol. 2020.

72. @ Richard Hoehn. Our editorial on \#COVID19 and socioeconomic disparities in cancer care. Twitter. May 2020 [Available from: https://twitter.com/Richard_Hoehn/status/ 1265259232548528134. .

73. Levine RL. Cancer did not stay home for COVID-19. American Association for the Advancement of Science; 2020.

74. Miranda P. Three months of COVID-19 may mean 80,000 missed cancer diagnoses | MDedge Hematology and Oncology. LinkedInMay 2020 [Available from: https://www.linkedin.com/ posts/paul-miranda-9ab53018_three-months-of-covid-19-maymean-80000-activity-6665015014153351168-iosG.

75. Hanna TP, King WD, Thibodeau S, Jalink M, Paulin GA, HarveyJones E, et al. Mortality due to cancer treatment delay: systematic review and meta-analysis. BMJ. 2020;371:m4087.

76. @ AACR. The \#AACR20 symposium on "Health Inequities and Disparities in the COVID-19 Pandemic and Impact on Cancer Care" is available for viewing. TwitterJuly 2020 [Available from: https://witter.com/AACR/status/1278765419961233410.

77. Dickman SL, Himmelstein DU, Woolhandler S. Inequality and the health-care system in the USA. Lancet. 2017;389(10077): $1431-41$.

78. Wilson JB, Jackson LR II, Ugowe FE, Jones T, Yankey GS Jr, Marts C, et al. Racial and ethnic differences in treatment and outcomes of severe aortic stenosis: a review. J Am Coll Cardiol Intv. 2020;13(2):149-56.

79. Williams DR, Jackson PB. Social sources of racial disparities in health. Health Aff. 2005;24(2):325-34.

80. Forde AT, Crookes DM, Suglia SF, Demmer RT. The weathering hypothesis as an explanation for racial disparities in health: a systematic review. Ann Epidemiol. 2019;33:1-18. e3.

81. Wang Z, Tang K. Combating COVID-19: health equity matters. Nat Med. 2020;26(4):458.

82. Chowkwanyun M, Reed AL Jr. Racial health disparities and Covid-19 - caution and context. N Engl J Med. 2020.

83. van Dorn A, Cooney RE, Sabin ML. COVID-19 exacerbating inequalities in the US. Lancet (London, England). 2020;395(10232):1243.

84. @NPR. African Americans are far more likely to have fatal heart conditions than other groups, a Yale epidemiologist says. TwitterApril 2020 [Available from: https://twitter.com/NPR/ status $/ 1245388477795098624 ? \mathrm{~s}=20$.

85. NPR. Underlying Health Disparities Could Mean Coronavirus Hits Some Communities Harder. NPR.April 2020 [Available from: https://www.npr.org/sections/health-shots/2020/04/01/ $824874977 /$ underlying-health-disparities-could-meancoronavirus-hits-some-communities-harde.

86. Haynes N, Cooper LA, Albert MA. Cardiologists AoB. At the heart of the matter: unmasking and addressing the toll of COVID-19 on diverse populations. Circulation. 2020;142(2): $105-7$.

87. @ CircAHA. Just Published Online: \#Perspective: at the heart of the matter: unmasking \& addressing \#COVID19's Toll on DIverse Populations May 2020 [Available from: https://twitter. com/CircAHA/status/1257356850439368708?s=20.

88. @NTucker_Oncology. A vast majority of the COVID-19-related deaths in NYC are among African American and Hispanic/Latino patients. Twitter. July 2020 [Available from: https:/twitter.com/ NTuckerOncology/status/1278817258702360576?s=20.

89. Ramirez R. As coronavirus ravages Louisiana, 'cancer alley' residents haven't given up the fight against polluters. GristMay 2020 [Available from: https://grist.org/justice/as-coronavirus-ravageslouisiana-cancer-alley-residents-havent-given-up-the-fightagainst-polluters/.

90. @ rachjuramirez. Instead, Formosa pointed to Louisiana's high rates of diabetes \& obesity TwitterMay 2020 [Available from: https://witter.com/rachjuramirez/status/1257302312579674112? $\mathrm{s}=20$.

91. @ AmericanHeartLA. We can \#EmPOWERChange to end inequities in health disparities based on social determinants. TwitterJune 2020 [Available from: https://twitter.com/ AmericanHeartLA/status/1270068055796744197?s=20.

92. Househ M, Borycki E, Kushniruk A. Empowering patients through social media: the benefits and challenges. Health informatics journal. 2014;20(1):50-8.

93. Hawkins CM, DeLaO AJ, Hung C. Social media and the patient experience. J Am Coll Radiol. 2016;13(12):1615-21.

94. Cardio-oncology During COVID19 Times - Supporting Healthcare Workers and Scientists marklu.net 2020 [Available from: https://marklu.net/preview/cardiooncology-collage/.

95. Chung RY-N, Dong D, Li MM. Socioeconomic gradient in health and the covid-19 outbreak. Bmj. 2020;369.

96. Yancy CW. COVID-19 and African Americans. Jama. 2020.

97. Bommakanti KK, Smith LL, Liu L, Do D, Cuevas-Mota J, Collins $\mathrm{K}$, et al. Requiring smartphone ownership for mHealth interventions: who could be left out? BMC Public Health. 2020;20(1):81.

98. Chen IY, Joshi S, Ghassemi M. Treating health disparities with artificial intelligence. Nat Med. 2020;26(1):16-7.

99. Hardeman AN, Kahn MJ. Technological innovation in healthcare: disrupting old systems to create more value for African American 
patients in academic medical centers. J Natl Med Assoc. 2020;112(3):289-93.

100. Breathett KK, Knapp SM, Wightman P, Desai A, Mazimba S, Calhoun E, et al. Is the affordable care act medicaid expansion linked to change in rate of ventricular assist device implantation for Blacks and Whites? Circ Heart Fail. 2020;13(4):e006544.

101. Turvey CL, Klein DM, Nazi KM, Haidary ST, Bouhaddou O, Hsing N, et al. Racial differences in patient consent policy preferences for electronic health information exchange. J Am Med Inform Assoc. 2020;27(5):717-25.

102. Kang JY, Kwon J, Sohn CH, Kim YJ, Lim HW, Lee SJ, et al. Big data-driven approach for health inequalities in foreign patients with injuries visiting emergency rooms. Healthe Inform Res. 2020;26(1):34-41.

103. Noseworthy PA, Attia ZI, Brewer LC, Hayes SN, Yao X, Kapa S, et al. Assessing and mitigating bias in medical artificial intelligence: the effects of race and ethnicity on a deep learning model for ECG analysis. Circ Arrhythm Electrophysiol. 2020;13(3):e007988.

104. McKendry RA, Rees G, Cox IJ, Johnson A, Edelstein M, Eland A, et al. Share mobile and social-media data to curb COVID-19. Nature. 2020;580(7801):29.

105. Thamman R, Gulati M, Narang A, Utengen A, Mamas MA, Bhatt DL. Twitter-based learning for continuing medical education?: A new perspective for a paradigm shift in medical education, accelerated by COVID-19. European Heart Journal. 2020.

Publisher's Note Springer Nature remains neutral with regard to jurisdictional claims in published maps and institutional affiliations. 